\title{
An Investigation on Spatial Variability of Selected Soil Parameters of Landscape under Mahogany in Wet Zone of Sri Lanka
}

\author{
Jayasinghe E.T.D. ${ }^{*}$, Perera P.K.P. ${ }^{1}$, Jayawardena D.T. ${ }^{1}$ and Jayakody A.N. ${ }^{2}$ \\ ${ }^{I}$ Department of Forestry and Environmental science, Faculty of Applied Sciences, University of Sri \\ Jayewardenepura,Gangodawila, Nugegoda, Sri Lanka. \\ ${ }^{2}$ Department of Soil Science, University of Peradeniya, Peradeniya, Sri Lanka. \\ *etdjayasinghe@gmail.com
}

\begin{abstract}
Soils show a wide variability in their macro and micronutrient contents and distribution. The spatial distribution of soil nutrients and physical parameters can be largely attributed to physical, chemical, and biological processes that undergo in different rates and different intensities in different localities. The availability of nutrients and the degree of interaction between these nutrients and the soil ultimately influence the vegetation that grows on a particular soil. Although past literature has investigated the spatial variability of soil parameters and correlation of soil parameters with various agricultural crops, few studies have examined such relationships in forest plantation landscapes. GIS has emerged as a valuable tool in visualizing and understanding spatial variability of soil parameters. Such soil parameter maps of large landscapes improve our understanding of the nature and extent of nutrient problems, as well as aid in exploring their possible relationships with various site factors such as slope, physical features, moisture and temperature etc.

The present study examined the spatial dependency of selected soil organic matters and nutrients on a 34-acre 8-year old mixed Mahogany stand in Wet Zone of Sri Lanka. Soil parameters of $\mathrm{pH}$, Total Organic Carbon, Total Nitrogen, Ammonium Chloride extractable K, Ammonium Chloride extractable $\mathrm{Mg}$, Ammonium Chloride extractable $\mathrm{Ca}$ was analysed using soil samples collected following a systematic grid point sampling method $(50 \mathrm{~m} \times 50 \mathrm{~m}$ grid).Accordingly, data from 44 soil sampling points were analysed using geostatistics and GIS techniques. Spatial distribution maps of above soil parameters were prepared in ArcMap 9.3 environment. The relationships of above soil parameters with various site specific attributes such as elevation, soil texture, proximity to drainage systems/streams were statistically examined.Results revealed that soil parameters tested show spatial heterogeneity along the landscape while showing correlations with selected site attributes. Implications of the findings in management of Mahogany forest crop are also discussed.
\end{abstract}

Keywords: Geostatistics, GIS, Spatial variability, Soil parameters, Mahogany 